\title{
Effects of propylene glycol supplementation on blood indicators of hepatic function, body condition score, milk fat-protein concentration and reproductive performance of dairy cows
}

\author{
Silviu Ionuț Borş ${ }^{1}$, Gheorghe Solcan ${ }^{2}$, Alina Vlad-Sabie ${ }^{2}$ \\ ${ }^{1}$ Development Research Station for Cattle Dancu, Iasi, Romania \\ ${ }^{2}$ University of Agricultural Sciences and Veterinary Medicine, Faculty of Veterinary Medicine, Iasi, Romania
}

Received February 5, 2013

Accepted October 23, 2013

\begin{abstract}
The aim of the present study was to determine the effects of propylene glycol on metabolic variables of hepatic function, body condition score, milk fat-protein concentration and reproductive performance of dairy cows after ending administration. Postparturient dairy cows $(n=200)$ of Holstein Friesian breed were divided into two groups of 100 individuals. The experimental group received during days 0-7 post partum an oral daily dose of $600 \mathrm{ml}$ of propylene glycol; the control group was without any supplement. The hepatic enzymes, glucose, cholesterol and serum albumin were measured on days 10-15, 45-50 and 70 post partum. Reproduction indicators of dairy cows were calculated from the farm recording data and the milk data record from a regular dairy control (days 10, 20,30, and 50 post partum). Animals that received propylene glycol in the first 7 days post partum had reduced activities of aspartate transaminase and gamma-glutamyl transferase, elevated cholesterol concentration $(P<0.05)$ and low milk fat percentage $(P<0.05)$ compared to control animals. Direct influence of propylene glycol drenching on the calving to first oestrus interval was observed, the smallest values being detected for the cows in the experimental group compared to the control group $(P<0.05)$. Our results suggest that some blood indicators of hepatic function, milk fat concentration and calving to first oestrus interval can be improved for 70 days post partum by the use of propylene glycol drenching in the first 7 days post partum. The beneficial effect of this treatment could be evaluated by easily available data, which can be used by practitioners in the field to analyze fertility problems in dairy herds and more exactly to examine whether metabolic stress, among other factors, is involved in the fertility problem.
\end{abstract}

Energy supplement, biochemical properties, body condition loss, reproductive indices, Holstein Friesian cows

The high producing dairy cow typically experiences a variable period of negative energy balance (NEB) during early lactation. The negative energy balance is usually assessed by predictors of energy status such as milk fat and milk protein. An increasing milk fat to protein ratio in cows in early lactation indicates a severe mobilization of fat reserves, resulting in elevated milk fat percentages (Butler 1998). Negative energy balance leads to lipomobilization with a high probability of fatty liver. Liver lesions caused by the accumulation of triacylglyceroles as a consequence of lipomobilization are typically observed in high producing cows during the first stage of lactation (Ametaj 2005). The main indicators of hepatic lesions and alterations of its function are the enzymes aspartate transaminase (AST), gamma-glutamyl transferase (GGT) and the blood metabolites glucose, cholesterol and albumin (Diaz González et al. 2011).

While negative energy balance during the first 3-4 weeks post partum is highly positively correlated with the interval of the first ovulation (Butler 2000), follicular growth and recruitment of a dominant follicle seem to be independent of the energy status (Beam and Butler 1997). Propylene glycol (PG) is frequently used as an oral drench in order to increase the molar percentage of ruminal propionate in the treatment of ketosis in postparturient dairy cattle, probably because of its ability to lower non-esterified fatty acid concentrations in blood (Grummer et al. 1994). Djoković et al. (2007) reported a 
significant increase of the concentration of glucose in blood after propionate infusion in healthy and ketotic cows.

The aim of the present study was to observe the effect of a daily oral drench (days 0-7 post partum) of propylene glycol $(600 \mathrm{ml}$ pro toto $)$ on blood indicators of hepatic function, body condition score, milk fat-protein concentration and reproductive performance of Holstein Friesian cows for 70 days after the parturition.

\section{Materials and Methods}

This study was conducted on 200 Holstein Friesian dairy cows in the North-East of Romania. The cows were randomly divided into two groups, (experimental E and control C) of 100 cows. Primiparous $(n=80)$ cows were paired according to the calving date, and multiparous $(n=120)$ cows were paired by the calving date, parity and prior milk production. One member of each pair was assigned randomly to experimental and control groups. After calving, both groups of cows were fed three types of food ration administered at different time intervals (Table 1).

Table 1. Ingredients and nutrient composition of diets for cows post partum.

\begin{tabular}{lccc}
\hline Ingredient & $0-7$ Days $p . p$. & $7-25$ Days $p . p$. & $>30$ Days $p . p$. \\
\hline Alfalfa hay (kg/day) & 5.5 & 5.5 & 5.5 \\
Corn silage (kg/day) & 18 & 22 & 24 \\
Protein supplement (kg/day) & 0.4 & 2.2 & 3.5 \\
Energy-protein supplement (kg/day) & 1.3 & 1.3 & 1 \\
Sun flour meal (kg/day) & 2 & 2.1 & 2 \\
Maize (kg/day) & 2.5 & 3.2 & 4 \\
Calcium-energy supplement (kg/day) & 0.15 & 0.25 & 0.4 \\
Calcium carbonate (kg/day) & 0.1 & 0.1 & 0.1 \\
Mineral supplement (kg/day) & & 0.1 & 0.1 \\
Quantity (kg/day) & 29.95 & 36.75 & 40.6 \\
Nutrient composition & & & \\
DMI (kg/day) & 17.98 & 22.15 & 24.62 \\
UFL & 16.34 & 20.53 & 23.35 \\
PDIN ( g/day ) & 1716 & 2384 & 2490 \\
PDIE ( g/day ) & 1585 & 2133 & \\
\hline
\end{tabular}

DMI - dry matter intake, UFL - milk fodder unit, PDIN - proteins digestible in the small intestine, which correspond to the food's nitrogen degraded in the paunch, PDIE - proteins digestible in the small intestine, which correspond to the food's energy fermented in the paunch, p.p. - post partum

Each cow in the experimental group $(\mathrm{n}=100)$ was given an oral dose of $600 \mathrm{ml}$ of propylene glycol once a day at 3-4 hours after the morning milking during days 0-7 post partum, while animals from control group were not supplemented.

Blood samples were obtained by jugular venipuncture, into the coagulation-activated vacuum tubes (Vacutest, Kima, Italia) on days 15,50 and 70 post partum. Every blood sample was centrifuged with the Rotofix $32 \mathrm{~A}$ (Hettich Lab. Technology, Germany) at $1,000 \times g$ for 15 min to obtain serum. Serum samples were transferred to the capped Eppendorf tubes and analyzed right away with the Accent 200, an automatic clinical chemistry analyzer (Pz Cormay S.A., Poland), using the photometric absorbance and nephelometric work principles.

The body condition score (BCS) was registered for each cow, right after the calving and also on day 70 post partum. The body condition was assessed by the same technician and was based on the six-point scale in which the score of 0 indicates severe emaciation and the score of 5 indicates obesity.

Milk production was recorded at each milking and milk samples were collected separately in morning milking on days 10,20, 30 and 50 of lactation for all animals. Milk fat-protein concentrations were determined by automated infrared analysis, using a Milkoscan 203 (Foss Electric, Hillerod, Denmark).

The reproduction indices were calculated using the reproduction charts available on the farm and also the computerized program of the milking stands (Madison, Wisconsin, USA - BouMatic ${ }^{\circledR}$ ), where all data regarding cow production and reproduction were registered. 
Each cow had a voluntary waiting period of 45 days post partum. Oestrus detection was carried out $\times 3$ daily using tail paint (which was first applied 15 days post partum) before and after the voluntary waiting period. The calving to first oestrus interval (CFEI) is defined as the interval from calving to the first observed behavioural oestrus in association with low $(<3 \mathrm{ng} / \mathrm{ml})$ progesterone concentrations on the day of observed oestrus (adapted from Royal et al. 2000). The period from calving to conception (CCI) was the difference between the date of conception and the date of the previous calving. An artificial insemination technician used semen from a single bull to serve the cows. The date of conception was estimated by subtracting 280 days from the calving date (Norman et al. 2009).

Data were tested for normal distribution using Shapiro-Wilk W test (Patrie and Watson 1999). Normally distributed data were subjected to ANOVA using propylene glycol administration as a fixed main effect and sampling period as a repeated measure (Patrie and Wats on 1999). The GGT, AST, albumin, glucose, cholesterol, fat-protein concentrations and reproductive indices (CFEI, CCI) between the two groups were compared, using Student's $t$-test or, when data were not normally distributed, with Mann-Whitney U test (Patrie and Watson 1999). The comparison of data from different sampling times was performed using paired Student's $t$-test. When data had normal distribution, the homogeneity of variances was determined using Levene's test (Patrie and Wats on 1999). The differences were considered significant when $P \leq 0.05$. Statistical evaluation of obtained data is in the text as mean \pm standard deviation.

\section{Results}

Gamma-glutamyl transferase and aspartate transaminase presented significantly $(P<0.05)$ higher values on day 15 post partum in group $\mathrm{C}$ compared to group $\mathrm{E}$. Nevertheless, in group C, GGT and AST presented a significant decrease $(P<0.05)$ of the mean on days 50 and 70 post partum compared to day 15 post partum (Fig. 1A, B).

Serum glucose presented higher values in group E compared to group C on day 70 post partum $(P=0.04)$. On day 70 post partum, both groups presented higher glucose values compared to day 15 post partum $(P<0.05)$.

Serum cholesterol presented higher values in group E compared to group $\mathrm{C}$ on day 15 post partum $(P=0.003)$. Serum cholesterol presented much higher values $(P<0.05)$ in both groups after day 50 post partum compared to day 15 post partum (Fig. 1D). No significant relationship was observed for serum albumin in both groups (Fig. 1E).

For group E, the body condition score declined from parturition $(3.2 \pm 0.13)$ to day 70 post partum $(2.9 \pm 0.12)$, but was not affected by the treatment $(P>0.05)$. For group $\mathrm{C}$, BCS did not show a significant change $(P>0.05)$ from parturition $(3.6 \pm 0.21)$ to day 70 post partum $(3.2 \pm 0.13)$.

No direct effect of the propylen glycol supplemented diet on the milk yield was observed during the experiment. The lactation curves in group $\mathrm{C}$ and $\mathrm{E}$ were similar regarding their variation and quantity $(P>0.05)$, and the milk production was 7,847 $\pm 1,461$ and $8,227 \pm$ $1,377 \mathrm{~kg}$ of milk per 305 days, respectively. Milk fat concentration was significantly lower in group $\mathrm{E}$ compared to group $\mathrm{C}$ on days $10(P=0.01)$ and $20(P=0.02)$ post partum (Fig. 2A). At the same time, milk fat concentration showed a significant decrease in group $\mathrm{C}$, beginning 30 days post partum $(P<0.05)$. Regarding milk protein values, no significant differences were found in any of the groups during the experiment (Fig. 2B).

A direct influence of the propylen glycol diet supplement on the calving to first oestrus interval was observed. The lowest values were found in dairy cows from group E (45.8 \pm 2.77 days $)$ compared to group $\mathrm{C}(78.2 \pm 4.6$ days $)(P<0.05)$. Calving to conception interval tended to be significantly lower $(P=0.06)$ in group $\mathrm{E}(75.4 \pm 9.44$ days $)$ compared to group $\mathrm{C}$ (94 \pm 15.3 days).

\section{Discussion}

Some diet energy supplement strategies using lipids (Moallem et al. 2007) or starch (Van Knegsel et al. 2007) have been described as good approaches for improving the energy balance in dairy cows; however, they had a negative effect on the function 

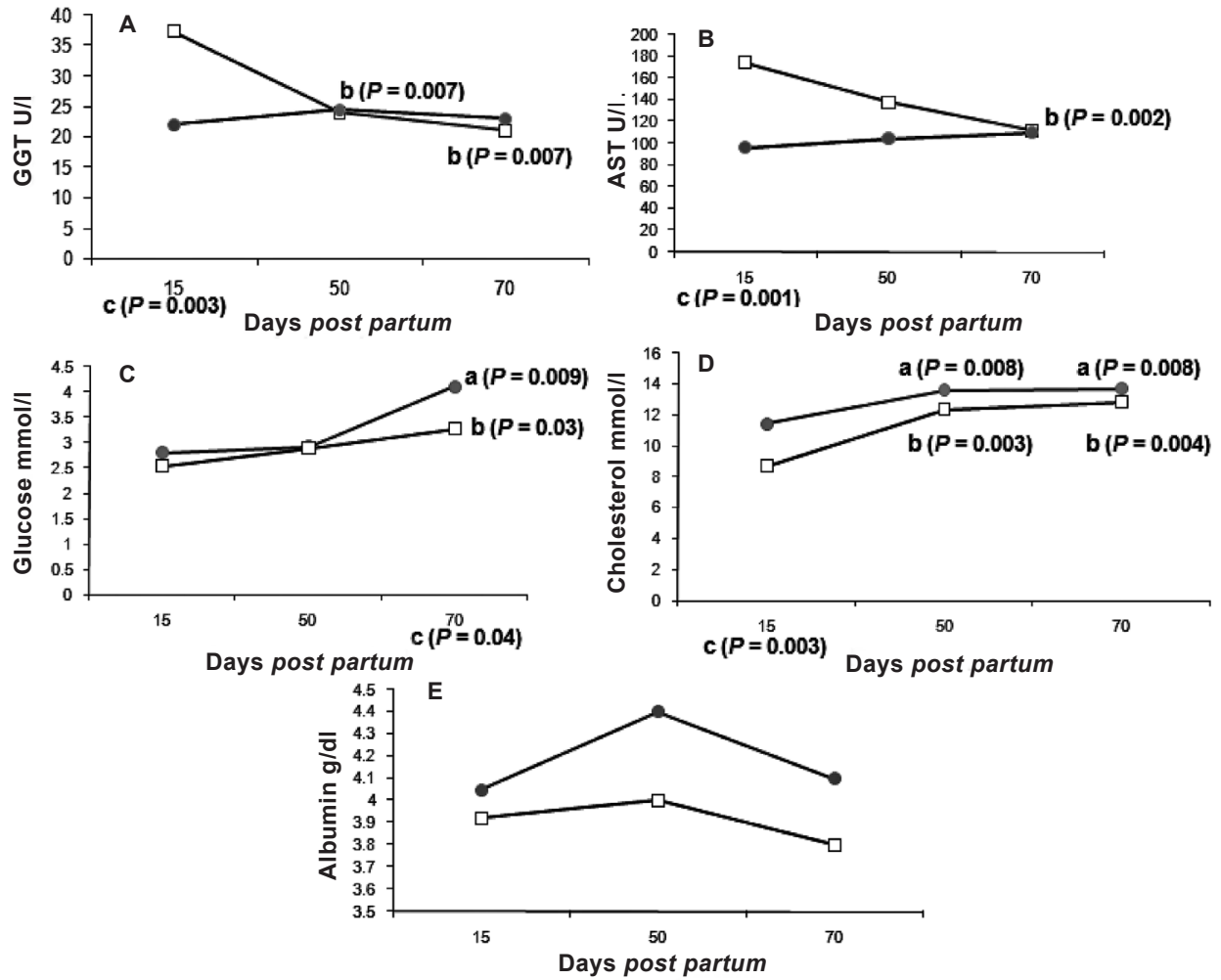

Fig. 1. Daily average changes of serum biochemical properties in cows fed with propylene glycol

A - gamma-glutamyl transferase (GGT) concentrations, B - aspartate transaminase (AST) concentrations, C glucose concentrations, D - cholesterol concentrations, E - albumin concentrations, $(\bullet)$ - experimental group supplemented with propylene glycol, ( $\square$ ) - control group (not supplemented), a - indicates differences $(P<0.05)$ in averages of serum biochemical properties in group $\mathrm{E}$, from those registered in day 15 post partum, $\mathrm{b}$ - indicates differences $(P<0.05)$ in averages of serum biochemical properties in group $\mathrm{C}$, from those registered in day 15 post partum, $\mathrm{c}$ - indicates the difference $(P<0.05)$ of means between these 2 groups at different time intervals $(15,50$ or 70 days post partum).

of the rumen and on the dry matter intake. Drenching with PG has long been known to increase plasma glucose in dairy cows (Butler et al. 2006). In our study, supplementation of propylene glycol to the cow at a dosage of $600 \mathrm{ml} /$ day on days $0-7$ post partum had no obvious effect on serum glucose concentration, after ending administration. Plasma glucose concentration increased from 15 to 70 days post partum more significantly in experimental group compared to control one, with significant difference being observed on day 70 post partum.

Fatty liver is a major metabolic disorder of many dairy cows in early lactation, lesions appear in the hepatic tissues and the activities of enzymes (AST, GGT) indicative of liver injury are generally augmented (Bobe et al. 2004). In our study, we found the value of $\operatorname{AST}(174.15 \pm 10.44 \mathrm{U} / \mathrm{L}$ equivalent $2.96 \pm 0.17 \mu \mathrm{kat} / \mathrm{L})$ on day 15 post partum in the control group similar to values found by Diaz González et al. (2011) in a cow with hepatic lesions. All data concerning liver enzymes suggested that PG supplementation has 

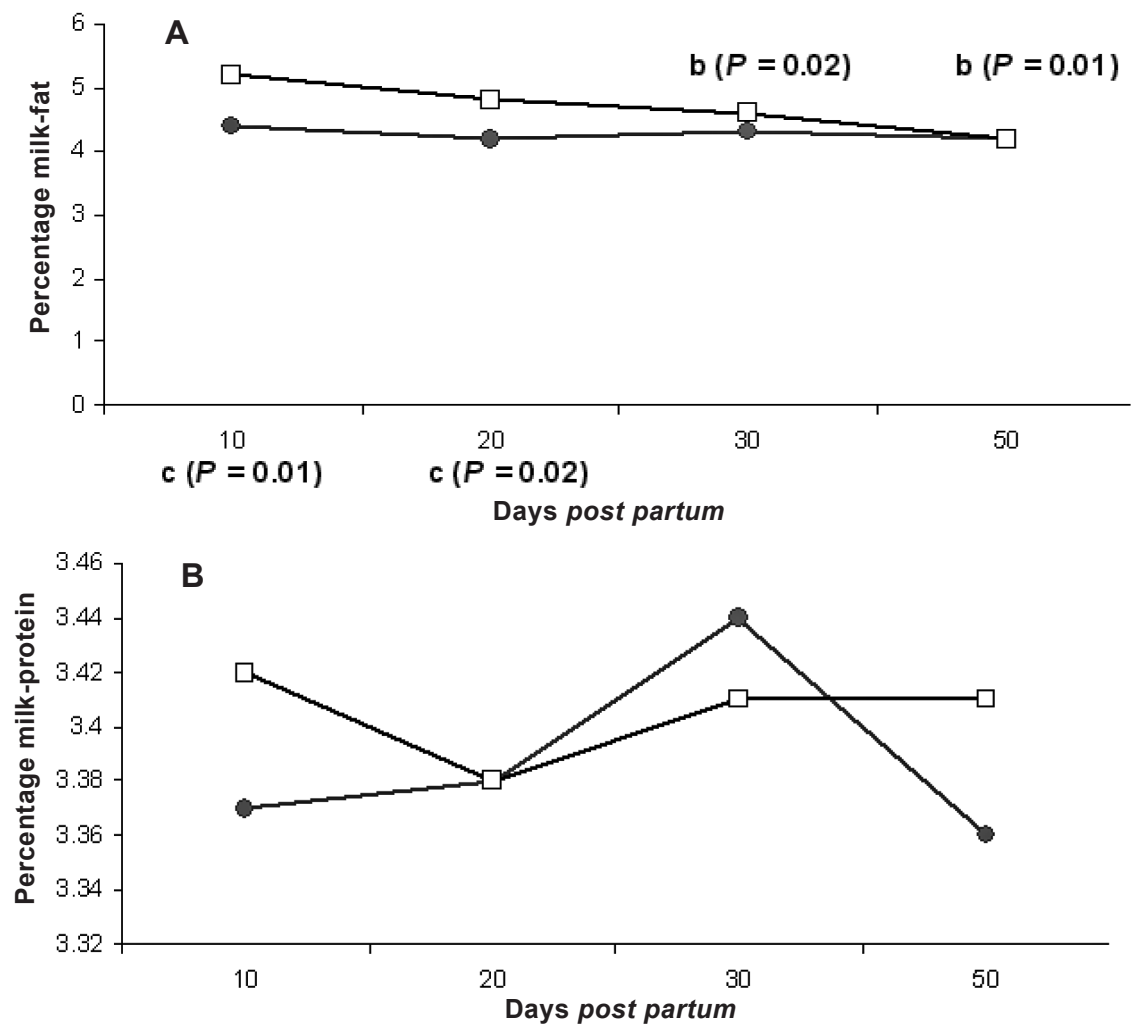

Fig. 2. Daily average changes of milk fat and protein percentages in cows fed with propylene glycol

A - Percentage milk-fat, B - Percentage milk-protein $(\bullet)$ - experimental group supplemented with propylene glycol, $(\square)$ - control group (not supplemented), a - indicates differences $(P<0.05)$ in the average of milk fat percentage in group $\mathrm{E}$, from those registered in day 10 post partum, $\mathrm{b}$ - indicates differences $(P<0.05)$ in average of milk fat percentage in group $\mathrm{C}$, from those registered in day 10 post partum, $\mathrm{c}$ - indicates the difference $(P<0.05)$ of means between these two groups at different time intervals $(10,20,30$ or 50 days post partum $)$.

the ability to reduce AST and GGT values after its administration and in consequence reduced liver lesions. In our study, we found that PG supplementation has the ability to increase the cholesterol level after the end of administration.

Heuer et al. (2001) have reported an association between milk yield and constituents and energy balance. Our study showed that milk yield in cows supplemented with PG was unchanged, that is in agreement with the findings of Lomander et al. (2012). Milk fat concentrations were significantly lower in PG treated group compared to the control group on days 10 and 20 post partum. Milk fat concentrations were unusually high for the control group on days 10 and 20 post partum. High values of milk fat content at the beginning of lactation suggest a possible degradation of the body fat deposit. An energy deficit stimulated the release of reserve fat, and it increased milk fat synthesis in the udder (Nogalski et al. 2012). It is possible that the PG supplement triggered an impaired fat release from the adipose tissue, a process that was reflected in the milk fat value variation. 
Fat mobilization from adipose tissue has many implications, some of which have been linked to poorer reproduction and health disorders (Duffield 2009). No valid relationship between the PG supplementation and BCS was observed, which is in agreement with the findings of Formigoni et al. (1996). Calving to first oestrus interval was significantly lower in the experimental group compared to the control $(P<0.05)$.

In conclusion, propylene glycol is a useful substance that can be supplemented to the diet of cows in the first 7 days after calving because PG can reduce AST and GGT values, increase the cholesterol level, reduce the milk fat percentage which coincided with a lower calving to first oestrus interval.

\section{Acknowledgements}

This study was funded by the research grant PN II 51-004/2007-2011 from CNMP (UEFISCDI) Bucharest, Romania.

\section{References}

Ametaj BN 2005: A new understanding of the causes of fatty liver in dairy cows. Adv Dairy Technol 17: 97-112

Beam SW, Butler WR 1997: Energy balance and ovarian follicle development prior to the first ovulation postpartum in dairy cows receiving three levels of dietary fat. Biol Reprod 56: 133-142

Bobe G, Young JW, Beitz DC 2004: Invited review: pathology, etiology, prevention, and treatment of fatty liver in dairy cows. J Dairy Sci 87: 3105-3124

Butler WR 1998: Review: effect of protein nutrition on ovarian and uterine physiology in dairy cattle. J Dairy Sci 81: 2533-2539

Butler WR 2000: Nutritional interactions with reproductive performance in dairy cattle. Anim Reprod Sci 60: 449-457

Butler ST, Pelton SH, Butler WR 2006: Energy balance, metabolic status, and the first postpartum ovarian follicle wave in cows administered propylene glycol. J Dairy Sci 89: 2938-2951

Diaz González F, Muiño R, Pereira V, Campos R, Benedito J 2011: Relationship among blood indicators of lipomobilization and hepatic function during early lactation in high-yielding dairy cows. J Vet Sci 12: 251-255

Djoković R, Šamanc H, Nikolić Z, Bošković Bogosavljević S 2007: Changes in blood values of glucose, insulin and inorganic phosphorus in healthy and ketotic dairy cows after intravenous infusion of propionate solution. Acta Vet Brno 76: 533-539

Duffield TF, Lissemore KD, Mcbride BW, Leslie KE 2009: Impact of hyperketonemia in early lactation dairy cows on health and production. J Dairy Sci 92: 571-580

Formigoni A, Cornil MC, Prandi A, Mordenti A, Rossi A, Portetelle D 1996: Effect of propylene glycol supplementation around parturition on milk yield, reproductive performance and some hormonal and metabolic characteristics in dairy cows. J Dairy Res 63: 11-24

Grummer RG, Winkler JC, Bertics SJ, Studer VA 1994: Effect of propylene glycol dosage during feed restriction on metabolites in blood of prepartum Holstein heifers. J Dairy Sci 77: 3618-3623

Heuer C, Van Straalen WM, Schukken YH, Dirkzwager A, Noordhuizen TM 2001: Prediction of energy balance in high yielding dairy cows with test-day information. J Dairy Sci 84: 471-481

Lomander H, Frössling J, Ingvartsen L, Gustafsson H, Svensson C 2012: Supplemental feeding with glycerol or propylene glycol of dairy cows in early lactation - Effects on metabolic status, body condition, and milk yield. J Dairy Sci 95: 2397-2408

Moallem U, Katz M, Arieli A, Lehrer H 2007: Effects of peripartum propylene glycol or fats differing in fatty acid profiles on feed intake, production, and plasma metabolites in dairy cows. J Dairy Sci 90: $3846-3856$

Nogalski Z, Wroński M, Lewandowska B, Pogorzelska P 2012: Changes in the blood indicators and body condition of high yielding Holstein cows with retained placenta and ketosis. Acta Vet Brno 81: 359-364

Norman HD, Wright JR, Kuhn MT, Hubbard SM, Cole JB, Vanraden PM 2009: Genetic and environmental factors that affect gestation length in dairy cattle. J Dairy Sci 92: 2259-2269

Patrie A, Watson P 1999: Statistics for veterinary and animal science. Blackwell Science Ltd., Oxford, pp. 83-103

Royal MD, Darwash AO, Flint APF, Webb R, Woolliams JA, Lamming GE 2000: Declining fertility in dairy cattle: changes in traditional and endocrine parameters of fertility. Anim Sci 70: 487-502

Van Knegsel AT, Van Den Brand H, Dijkstra J, Van Straalen WM, Jorritsma R, Tamminga S 2007: Effect of glucogenic vs. lipogenic diets on energy balance, blood metabolites, and reproduction in primiparous and multiparous dairy cows in early lactation. J Dairy Sci 90: 3397-3409 